\title{
Digital Fluid Technologies for the Steel Industry
}

\author{
Rudolf ScheidI', Bernd Winkler², Helmut Kogler², Peter Ladner², Rainer Haas², and Evgeny Lukachev \\ ${ }^{1}$ Institute of Machine Design and Hydraulic Drives, Johannes Kepler University Linz, Linz, Österreich \\ ${ }^{2}$ Linz Center of Mechatronics $\mathrm{GmbH}$, Linz, Österreich
}

Received September 30, 2016; accepted October 5, 2016; published online October 27, 2016

\begin{abstract}
Digital fluid systems are controlled solely by onoff valves, in contrast to analogue fluid systems which use continuously adjustable valves. Many digital fluid systems have been in practical use for some decades. The steel industry relies on several fluid technologies. Apart from the handling of the liquid steel, several other fluid processes exist to fulfill indispensable functions; examples include cooling, motion control, torch cutting, descaling, and lubricating. Many of these processes need better control concerning precision, dynamics, resource demand, reliability, and environmental impact or must offer additional functionalities for use in factories of the future. In several cases digital fluid systems are the better solutions. In this paper this is demonstrated by four examples, ranging from proven simple solutions and concepts going currently into industrial application to promising concepts for the future.
\end{abstract}

Keywords: Digital fluid systems, Pulsed cooling, Gap control, Continuous casting segment adjustment, Oscillation drive

Digitale Fluidtechniken für die Stahlindustrie

Zusammenfassung: Digitale Fluidtechniken verwenden Schaltventile zur Steuerung bzw. Regelung. Sie sind ein Gegenstück zu analogen Fluidsystemen, die mit Analogventilen arbeiten. Zahlreiche digitale Fluidsysteme sind seit Jahrzehnten in Verwendung. Die Stahlindustrie bedient sich vielfacher Fluidtechniken. Neben jenen zur Handhabung des Flüssigstahles sind solche zur Kühlung, Bewegungssteuerung, zum Brennschneiden, Entzundern und zur Schmierung unverzichtbar. Viele dieser Prozesse sollten besser geführt werden hinsichtlich Genauigkeit, Dynamik, Ressourcenverbrauch, Zuverlässigkeit, Umweltbelastung, oder zur Realisierung zusätzlicher Funktionen

Univ.-Prof. DI Dr. R. Scheidl ( $\square$ )

Institute of Machine Design and Hydraulic Drives,

Johannes Kepler University Linz,

Altenbergerstraße 69,

4040 Linz, Österreich

rudolf.scheidl@jku.at für Industrie 4.0. In vielen Fällen sind digitale Fluidsysteme die besseren Lösungen. In diesem Aufsatz wird das anhand von vier Beispielen gezeigt. Sie reichen von einfachen, bereits bewährten Systemen über Konzepte, die derzeit ihre erste industrielle Umsetzung erfahren, bis hin zu aussichtsreichen Konzepten für die Zukunft.

Schlüsselwörter: Digitale Fluidtechnik, Gepulste Kühlung, Walzspaltregelung, Segmentverstellung,

Oszillationsantrieb

\section{Introduction - A Brief of Digital Fluid Control}

Fluid systems play a strong role in steel production, for cooling, torch cutting, descaling, lubricating, and for motion generation. They need improvement to fulfill the required excellent performance of future production systems, in terms of product quality, yield, productivity, and work safety.

Digital Fluid Power is a current trend, primarily in the area of hydrostatic drives. It is defined as the control of fluid power drives by on-off valves. This definition suggests a generalization of fluid systems in general, since the application of on-off valves for control is useful also beyond the generation of mechanical motion or force. The large variety of such systems can be classified into on-off, switching, and parallel technologies (see table in Fig. 1).

In on-off methods the different switching states of the valves correspond to a stationary operation phase of the hydraulic system. The time between consecutive valve operations is related to characteristic times of the process to be operated. Dynamical effects of switching in the hydraulic and mechanical parts of the complete system are negligible. The system described in Section 2.1 is a successful on-off method application in continuous casting. Such systems are very simple, robust, and cheap. Dynamical performance and accuracy, however, are limited.

In switching control the switching frequency is higher than the bandwidth of the process to be controlled, e.g. the 


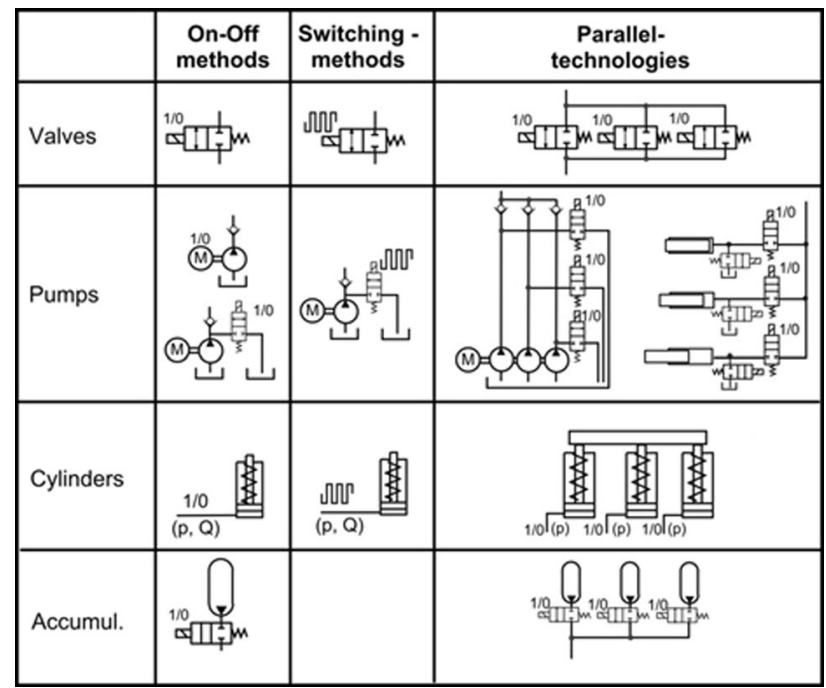

Fig. 1: Classification of digital fluid power of Linjama ([1])

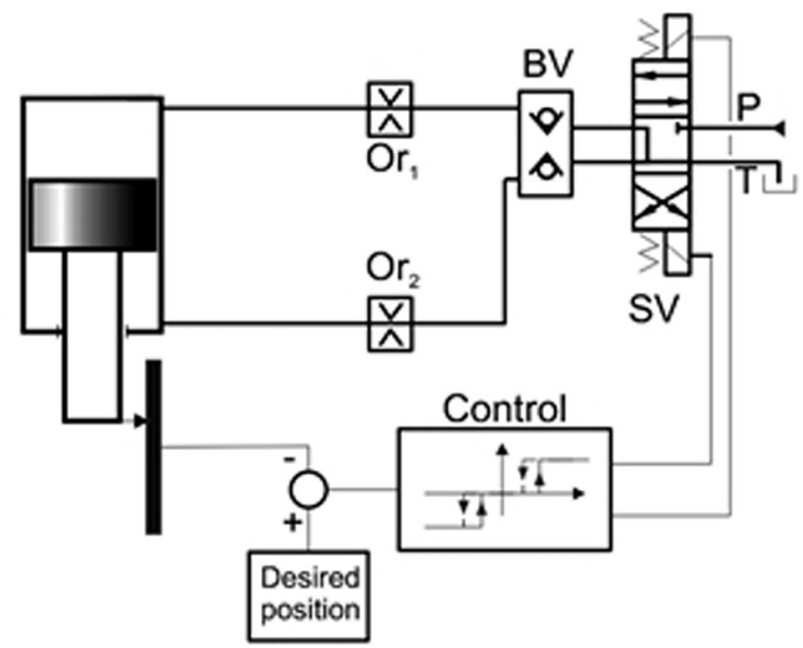

Fig. 2: Schematic of the hydraulic drive for remote adjustment of CC segments
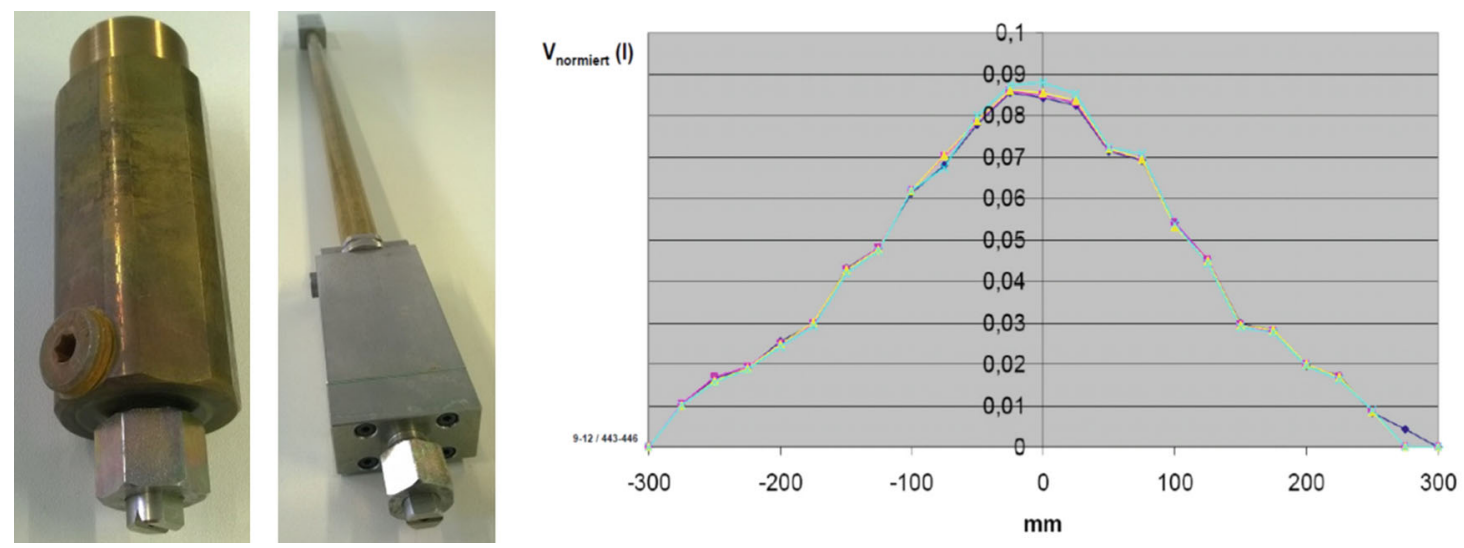

Fig. 3: Two types of the integrated nozzle-valve unit and a typical relative water distribution (related to the maximum flow rate in the centre point for each case) in lateral direction for different duty-cycles $\left(f_{P W M}=1 \mathrm{~Hz}\right)$ 
Fig. 4: Schematics of a hydraulic gap control actuator with an analogue, i.e. servo valve, and a digital control

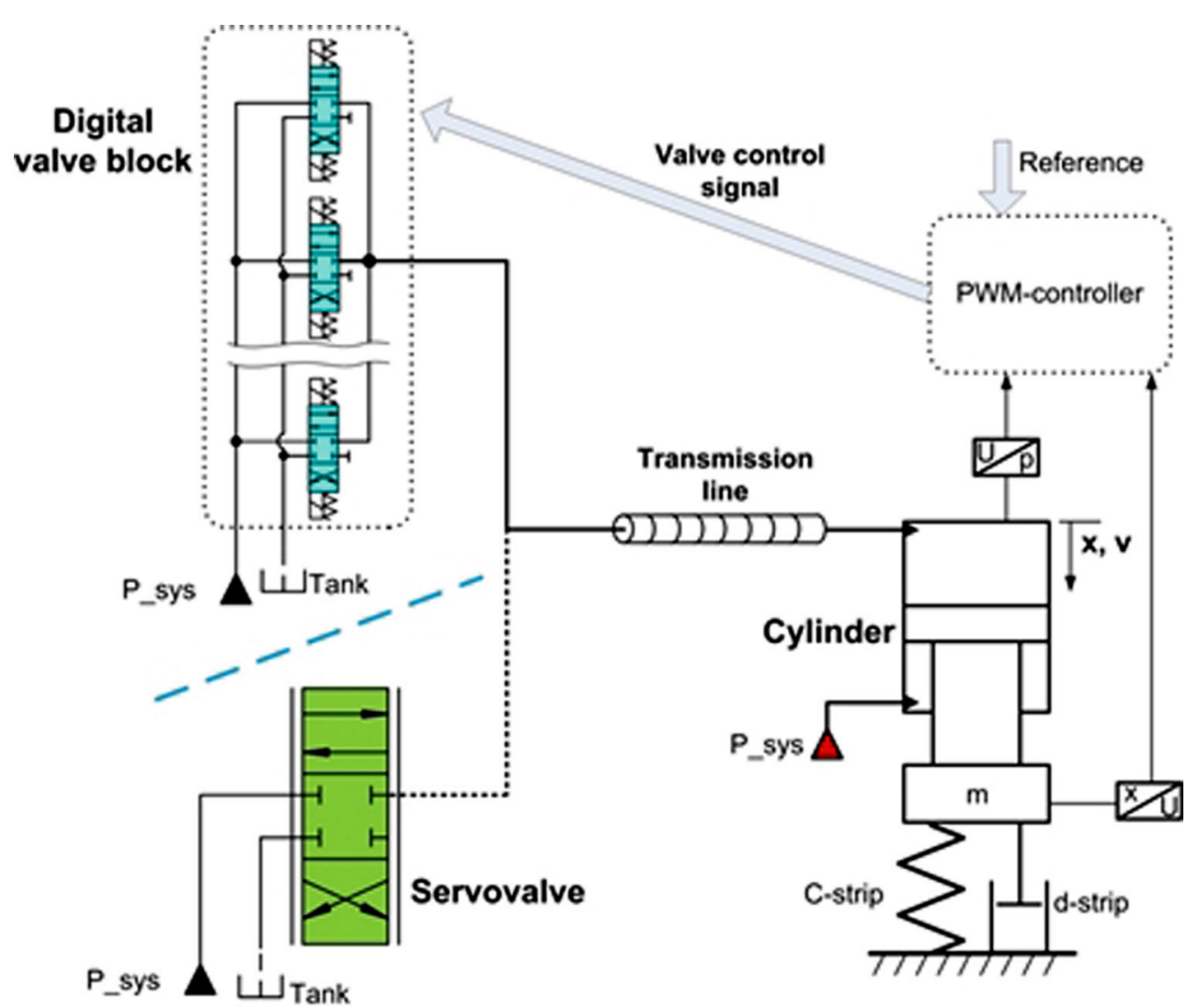

bang control can be applied because of the small positioning speed required of $0.2 \mathrm{~mm} / \mathrm{sec}$ only. The major advantages of this concept are: (i) The high robustness against oil contamination of the used components compared to servo valves; (ii) lower cost, since switching valves are much cheaper than servo or proportional valves.

\subsection{Pulsed Secondary Cooling}

A digital concept promises the enabling of a drastically refined secondary cooling for continuous casting (CC) by controlling the flow of each spray nozzle. Concerning local cooling intensity, water nozzles achieve a maximum cooling range of 1:3, air-mist nozzles up to $1: 9$, without jeopardizing cooling uniformity. The system must work robustly under the harsh conditions of CC. A proportional control of the volume flow for each nozzle has three major drawbacks: (i) It requires air mist cooling systems if the cooling rate range is to go beyond 1:3; they cause high investment and energy costs; (ii) the small orifices in the corresponding flow control valves endanger the robustness against contaminated cooling water; (iii) the environmental CC conditions require the proportional valve to be located in a protected area and the complexity of piping would dramatically increase for these several hundred of valve and nozzle pairs.

A basic idea to resolve this conflict is to apply pulsewidth modulated cooling (PWMC) [12]. The cooling intensity is controlled by switching the spray nozzles of the secondary strand cooling periodically on and off. In [13], the temperature fluctuations in the strand due to periodic switching were shown to be much less than those at the cooling zone boundaries of state of the art secondary cooling systems. A method to detect defect valves or clogged nozzles was derived in [14].

In the selected concept, the water valve is pneumatically piloted and located closely to the nozzle to shorten the pressure build up time in the volume between nozzle and valve and, in turn, the formation of the steady state spray pattern. The pneumatic pilot valve is placed in a safe distance from the strand encapsulated in a control box.

To guarantee robustness, the water valve is realized as a seat type valve in a special design concerning sealing and valve seat. The pilot valve is a 3-port/2-way pneumatic valve available as standard component on the market.

Measurements of a developed valve prototype with different pneumatic and water pressure levels showed that a uniform spray can be obtained up to a flow rate range larger than 1:10, which outperforms even that of current air mist nozzles. An example measurement is shown in Fig. 3. A further promising result of these measurements is the fairly linear relationship between duty cycle and the average water flux and, in turn, with the average cooling rate. Tests at CC machines showed sufficient robustness of the system in the very harsh operating conditions. 


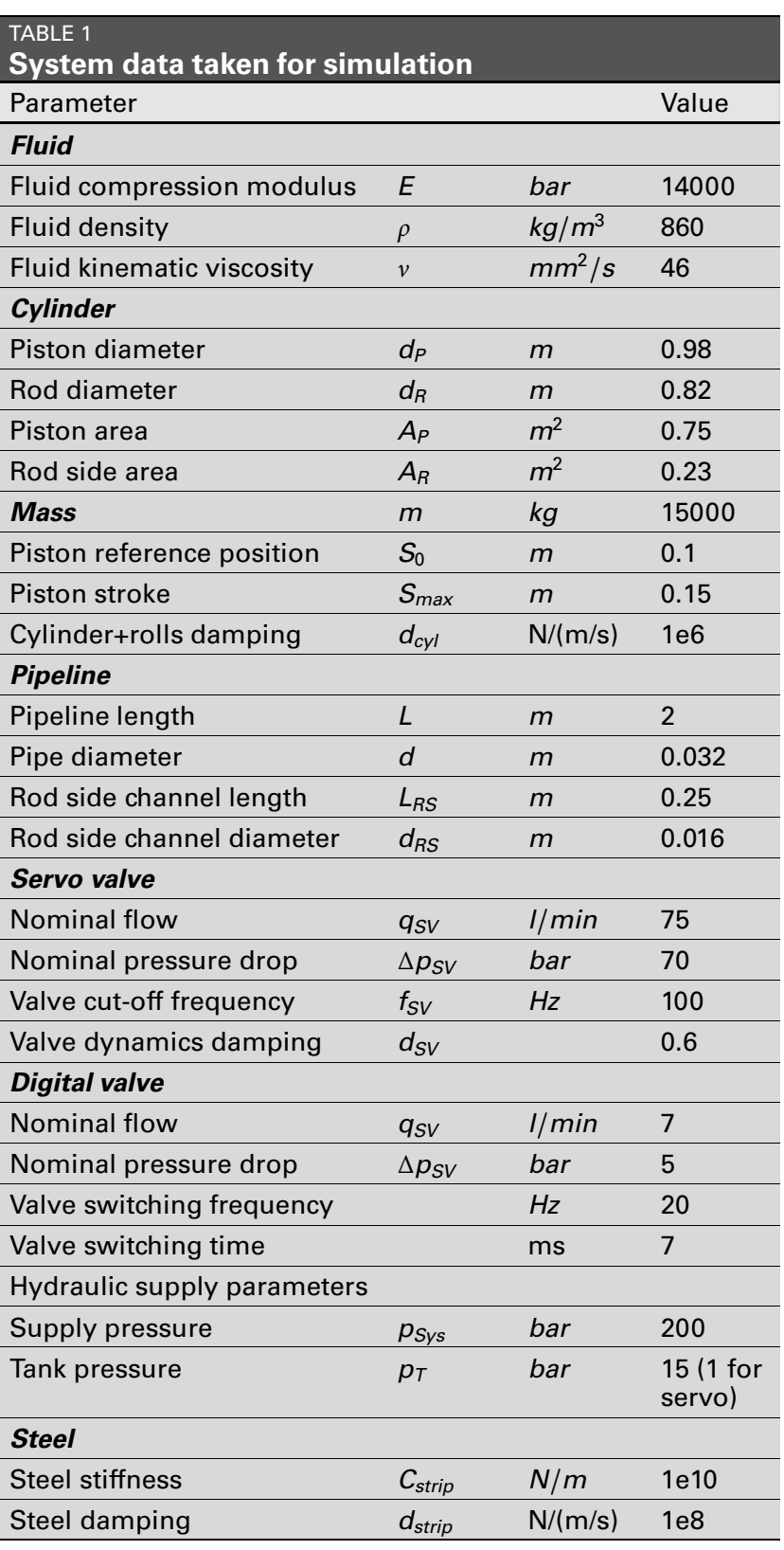

\subsection{Hydraulic Gap Control for Rolling Mills}

Hydraulic gap control is done with high bandwidth and very accurate servo valves. The operation frequencies for position control have currently a bandwidth of 25 to $30 \mathrm{~Hz}$. The use of servo valves has three main disadvantages: (i) The high oil cleanliness requirements which are difficult to fulfill in the crude condition of a rolling mill; (ii) the high power demand for leakage losses and valve piloting which make up $80 \%$ to $90 \%$ of the consumed power in a typical operation scenario, as found in [15]; (iii) the frequent replacement of the expensive valves due to wear of the metering edges. A project of the Linz Center of Mechatronics has shown that the required dynamical performance can be achieved with digital hydraulic control principles.
In Fig. 4 the schematics of gap control with analogue and digital principles is shown. Both systems were numerically simulated for system data according to Table 1, taking into account also a transmission line between the valves and the hydraulic cylinder. For the digital version, a currently merchantable valve which is qualified for digital applications was considered in this case to show the feasibility of the concept with state of the art components. The moderate nominal flow rate requires six of these valves to achieve the required positioning speed. The results in Fig. 5 show a performance comparable to that of servo valves with the expected benefit of higher robustness, longer lifetime, and considerable energy savings.

\subsection{Mold Oscillation by Switching Control}

In continuous casters the mold must be oscillated with a peak-to-peak stroke of several millimeters and a frequency of some hertz. For the analysis done in this paper, a stroke $7 \mathrm{~mm}$ and a frequency of 5 hertz are taken. Today, in advanced conventional casters, the mold oscillation is realized by a hydraulic proportional servo drive (HPD) as depicted in Fig. 6 on the right hand side. As an energy efficient alternative, a hydraulic buck converter (HBC, see for instance $[16,17])$ shown on the left hand side in Fig. 6 is studied. The HBC represents a hydraulic switching converter, which operates at a constant switching frequency in pulse-width-mode. It uses the spill-over of kinetic energy of the hydraulic fluid in a pipe line in order to draw energetically cheap oil through check valves from tank to a higher pressure level, which results in a significant higher energy efficiency than resistance control. In the opposite flow direction, the HBC is able to recuperate energy. The output of the converter is connected to a conventional dual stroke cylinder, which drives the mold in this specific case. The HBC uses a hydraulic accumulator at its output for smoothing the pressure ripples due to switching. The accumulator decreases the natural frequency of the drive; however, the energy efficiency can be even further improved, if this frequency comes close to the operation frequency (see, for instance, [18]).

The simulation results in Fig. 7 show considerably lower energy consumption compared to resistance control, which would result also in lower installation costs.

\section{Conclusions}

Digital fluid systems have a high potential to provide innovative solutions for fluid control in the steel industry. The advantages which can be achieved depend on the specific application and can typically be: Higher robustness and lifetime, lower power consumption and installation costs, easier maintenance, easier realization of failure detection and predictive maintenance functions. In some cases they can be realized with existing components, in particular with existing valves which are the key components of such systems. Yet, there are challenges: More advanced components, e.g. faster valves with a higher operating frequency, 
Fig. 5: Step response simulation results for a typical rolling mill situation for a servo valve and a digital concept with six merchantable valves; upper diagram shows the cylinder position, lower diagram the valve responses


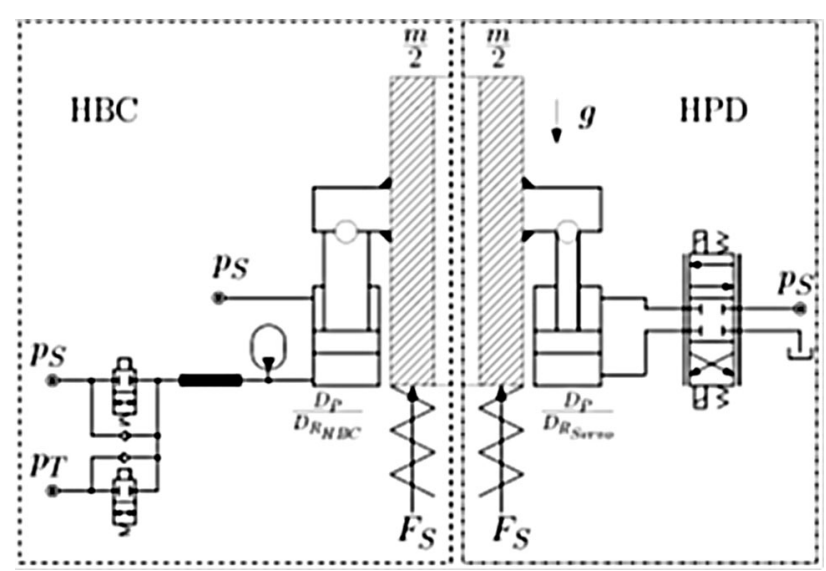

Fig. 6: Mold oscillation control; right: conventional hydraulic proportional drive; left: hydraulic switching control using a hydraulic buck converter (HBC)
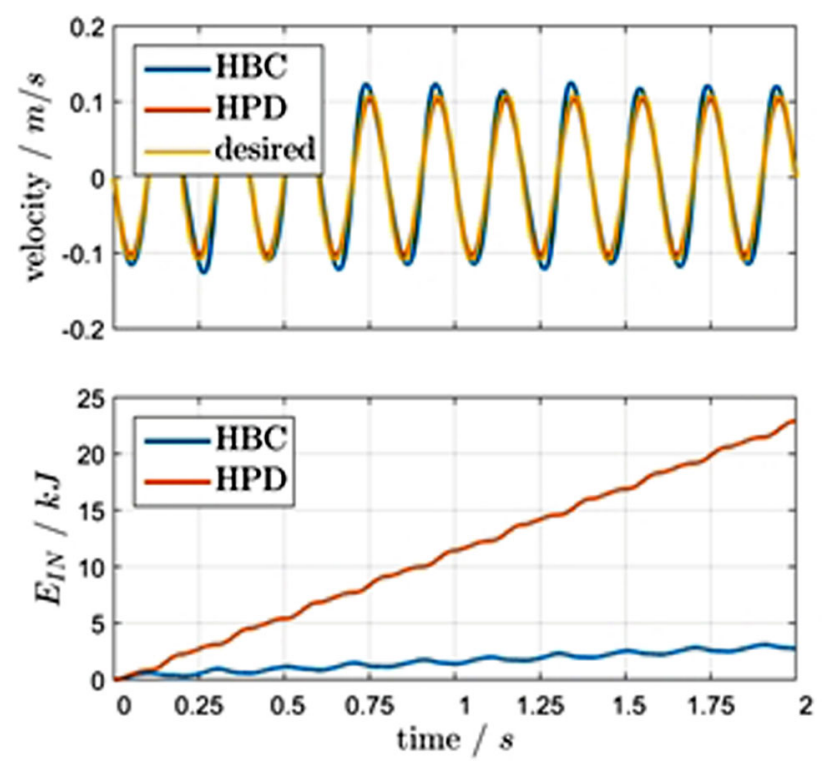

Fig. 7: Piston velocity and energy consumption of the HPD compared to the HBC drive high response accumulators with a high lifetime even at frequent and intensive charges and discharges, and the handling of pulsation and noise problems which are created by frequent switching.

In future, the enabling of functions required in Industry 4.0 environments will pose additional requirements on fluid systems. Depending on the specific situation, digital fluid systems can have striking advantages for that [19].

A broad success of digital fluid control needs powerful components, the understanding of the system dynamics, appropriate control methods, and, most importantly, a clever solution concept tailored for each application.

Acknowledgements. Main parts of this work have been carried out at $\mathrm{LCM} \mathrm{GmbH}$ as part of a K2 project. K2 projects are financed using funding from the Austrian COMET-K2 program. The COMET K2 projects at LCM are supported by the Austrian federal government, the federal state of Upper Austria, the Johannes Kepler University and all of the scientific partners which form part of the K2-COMET Consortium.

Open access funding provided by Johannes Kepler University Linz.

Open Access This article is distributed under the terms of the Creative Commons Attribution 4.0 International License (http://creativecommons.org/licenses/by/4 $0 /$ ), which permits unrestricted use, distribution, and reproduction in any medium, provided you give appropriate credit to the original author(s) and the source, provide a link to the Creative Commons license, and indicate if changes were made.

\section{References}

1. Linjama, M.: Digital Fluid Power - State of the Art, in: Sairiala, $H_{\text {. }}$; Koskinen, K. (eds.): Proc. of the Twelfth Scandinavian International Conference on Fluid Power, Volume 2 (2011) no. 4, SICFP'11, Tampere, Finland, May 18-20, 2011

2. Scheidl, R.; Kogler, H.: Hydraulische Schaltverfahren: Stand der Technik und Herausforderungen, O+P Journal, 2013, no. 2, pp 6-18.

3. Meßner, F.; Scheidl, R.: Development and Experimental Results of a Small Fast Switching Valve Derived from Fuel Injection Technology, in: Uusi-Heikkilä J., Linjama M. (eds.): Proceedings of the Eight Workshop on Digital Fluid Power, May, 2016

4. Haas, R.; Lukachev, E.: Optimal Feed-Forward Control of a Digital Hydraulic Drive, Journal of Systems and Control Engineering, submitted and accepted, 2016, doi:10.1177/0959651816640622 
5. Linjama, M.; Koskinen, K. T.; Vilenius, M.: Pseudo-Proportional Position Control of Water Hydraulic Cylinder Using On/Off Valves. The Fifth JFPS International Symposium on Fluid Power, Vol. 2002 (2002), no. 5-1, November 12-15, 2002, Nara, Japan, pp 155-160, doi: http://doi.org/10.5739/isfp.2002.155

6. Siivonen, L.; Linjama, M.; Huova, M.; Vilenius, M.: Jammed On/Off Valve Fault Compensation with Distributed Digital Valve System. International Journal of Fluid Power, 10 (2009), no. 2, pp. 73-82, doi: 10.1080/14399776.2009.10780979.

7. Siivonen, L.; Linjama, M.; Huova, M.; Vilenius, M.: Pressure based fault detection and diagnosis of a digital valve system, in: Johnston, D. N.; Plummer, A. (eds.): Power Transmission and Motion Control (PTMC07), September 12-14, 2007, Bath, UK, pp 67-79

8. Scheidl, R.; Linjama M.; Schmidt, S.: Discussion: Is the Future of Fluid Power Digital?, in: Proceedings of the Institution of Mechanical Engineers, Part I, Journal of Systems and Control Engineering, 226 (2012), no. 6, pp 724-727, doi: 10.1177/0959651811435628

9. Linjama, M.: Energy Saving Digital Hydraulics. in: Scheidl, R.; Winkler, B. (eds.): Proceedings of the Second Workshop on Digital Fluid Power, November 12-13, 2009, Linz, Austria, pp 5-20

10. Meßner, F; Scheidl, R.; Haas, R.; Gattringer, H.; Springer K.: A Combined Variable Displacement - Digital Cylinder Hydraulic Drive for Large Presses with High Operating Frequencies, in: Journal of Dynamic Systems, Measurement and Control, 138 (2016), no. 7, pp 074502-1-074502-5

11. Brandstetter, R.: Untersuchung von Antriebskonzepten für die automatische Gießdickenverstellung bei Stranggießanklagen mit segmentierter Strangführung, Diploma thesis, Johannes Kepler University Linz, Institute of Machine Design and Hydraulic Drives, 1996

12. Ladner, P.; Scheidl, R.; Mairhofer, M.; Wahl, H.: A Switching Technique for Metal Cooling, in: Scheidl, R. (ed.): Proceedings of the
Fourth Workshop on Digital Fluid Power, September 21-22, 2011, Linz, Austria, pp 169-182, 2011

13. Wöss, S.: Theoretische Untersuchung über die Temperaturentwicklung beim Puls-weitenmodulierten Kühlen in Stranggussanlagen, Master thesis, Johannes Kepler University Linz, Institute of Machine Design and Hydraulic Drives, 2012

14. Stellnberger, R.: Automatische Fehlererkennung in einem Pulsweitenmodulierten Sekundärkühlsystem für Stranggußanlagen, Master thesis, Johannes Kepler University Linz, Institute of Machine Design and Hydraulic Drives, 2013

15. Krieger, A.: Untersuchungen zum Energieverbrauch von hydraulischen Antriebssystemen eines Walwerkes, Master thesis, Johannes Kepler University Linz, Institute of Machine Design and Hydraulic Drives, 2014

16. Kogler, H.; Scheidl R.: Two basic concepts of hydraulic switching converters, In: Linjama M., Laamanen A. (eds.): Proceedings of the First Workshop on Digital Fluid Power, DFP08, Tampere, Finland, 2008, pp 113-128

17. Kogler, H.: The Hydraulic Buck Converter - Conceptual Study and Experiments, PhD thesis, Johannes Kepler University, Institute of Machine Design and Hydraulic Drives, Linz, Austria, 2012

18. Kogler H., Scheidl R.: Hydraulic Switching Control of Resonant Drives, in: Proceedings of the 12th Mechatronics Forum Biennial International Conference, 28-30 June 2010, Swiss Federal Institute of Technology, ETH Zurich, Switzerland, 2010, pp 97-102

19. Brandstetter, R.; Deubel, T.; Scheidl, R.; Winkler, B.; Zeman, K.: Digital Hydraulics and "Industrie4.0", in: Proceedings of the Institution of Mechanical Engineers, Part I, Journal of Systems and Control Engineering, 2015, doi: 10.1177/0959651816636734 